\title{
Urban Vegetable Farmworkers Beliefs and Perception of Risks Associated with Pesticides Exposure: A Case of Gaborone City, Botswana
}

\author{
Gobusamng Leungo ${ }^{1}$, Motshwari Obopile ${ }^{1}$, Otsoseng Oagile ${ }^{1}$, Mogapi E. Madisa ${ }^{1} \&$ Yoseph Assefa $^{1}$ \\ ${ }^{1}$ Department of Crop Science and Production, Botswana College of Agriculture, University of Botswana \\ Correspondence: Motshwari Obopile, Department of Crop Science and Production, Botswana College of \\ Agriculture, University of Botswana, Gaborone, Botswana. E-mail: mobopile@gmail.com
}

Received: February 2, 2012 Accepted: March 19, 2012 Online Published: August 15, 2012

doi:10.5539/jps.v1n2p114 URL: http://dx.doi.org/10.5539/jps.v1n2p114

\begin{abstract}
A survey was conducted in urban horticultural setting in Gaborone City, Botswana from $4^{\text {th }}$ to $31^{\text {st }}$ March 2010 by interviewing 56 farmworkers on their perception and knowledge of risks and hazards associated with exposure to pesticides. The study showed that most farmers relied heavily on pesticides and applied them without considering economic damage to crop. Most pesticides used are classified as extremely hazardous by the World Health Organisatopn (WHO). Majority of farmworkers were aware of health risks and environmental contamination associated with pesticides. The awareness of pesticide harm was significantly influenced by educational background, training on pesticide use and experience on vegetable production. While the percentage of educated and experienced workers was higher (> 50\%), training from extension services was only $14 \%$ indicating the need for more training to maintain the awareness standard. The study needs to be done in other urban centres of Botswana to get countrywide information on farmworkers awareness of pesticide harm.
\end{abstract}

Keywords: farmworkers, beliefs, pesticide exposure, vegetables

\section{Introduction}

The United Nations (UN) population fund (2007) reported that more than $50 \%$ of the world's population was living in urban areas. The trend has also been reported in Botswana where a dramatic increase in urban population was more than $60 \%$ in 2006 (CSO, 2006). Improved food supply and distribution systems are necessary to address increasing levels of urban food insecurity, while ensuring higher farmer incomes (FAO 2006). The Botswana Ministry of Agriculture has advocated for introduction of urban agriculture to meet demands for food in urban areas (Madisa et al., 2010). Introduction of urban horticulture to increase horticultural productivity requires inputs that include pesticides to control pests and diseases (Obopile et al., 2008; Madisa et al., 2010).

Improper use of pesticides reduces agricultural sustainability by causing environmental problems such as underground and surface water pollution. Over-use of pesticides also destroys beneficial organisms, resulting in acquirement of resistance by pests and has harmful effects on the health of humans and wildlife (Pedigo \& Rice, 2006). In the developed countries, there is greater awareness of the harmful effects of pesticides and this had led to better regulation of pesticides and compulsory training of spray operators and/or routine checks on spraying equipment (Delen et al., 2005).

The World Health Organization and the UN Environment Programme estimate that each year, three million workers in agriculture in the developing world experience severe poisoning from pesticides, about 18,000 of whom die (Miller, 2004). Horticultural crops attract high applications of pesticides, and farmers in developing countries use many toxic pesticdes to control pests on these crops (Dinham, 2003). Farmers in developing countries rarely have access to training in pesticide use, and have only limited or no access to advice on the complicated management of pesticides. Farmers' knowledge of product selection, application rates and timing of pesticides application is also lacking.

Studies on risks associated with pesticides, farmer practices and behavior when handling chemicals is crucial in making efforts to reduce the dangers associated with pesticides use in horticulture. Comparisons between farmers and farmworkers beliefs and knowledge of chemical exposure have been explored elsewhere (Vaughan, 
1993; Quandt et al., 1998; McCauley et al., 2002). Limited information is available on pesticide knowledge and risk perceptions of agricultural farmworkers in Botswana. Obopile et al. (2008) studied farmers' knowledge, perceptions and management of vegetable pests and diseases in Botswana but did not consider risks and hazards associated with farmworkers' practices and behaviors when handling pesticides.

In this study we evaluated work practices, pesticide risks, beliefs, knowledge of pesticide and hazards among vegetable farmworkers in peri-urban areas of Botswana. We wanted to determine if certain demographic characteristics are associated with knowledge of hazards associated with pesticide exposure. We examined the influence of pesticide knowledge and health beliefs on work practices such as wearing protective clothing when handling pesticides.

\section{Methodology}

The survey was conducted in urban and peri-urbun areas surrounding Gaborone city ( $\left.24^{\circ} 57^{\prime} \mathrm{S} ; 25^{\circ} 95^{\prime} \mathrm{E}\right)$ from $4^{\text {th }}$ to $31^{\text {st }}$ March 2010. A total of 56 respondents were interviewed. A face to face interview was done by means of an open ended questionnaire in Setswana and/or in English. The sample size of the farmworkers interviewed was based on availability of farmworkers. The theme of the questions centred on pesticides knowledge, health beliefs and risk perceptions of vegetable farmworkers but there were questions on crop species and pests associated with them. We also interviewed farmworkers on the methods used to control pests and diseases and frequency of pesticide application. In addition to questions defining personal characteristics such as age, educational status and vegetable production experience, farmworkers were also asked questions aimed at safety during pesticide application including the use of protective clothing and reading of pesticide labels.

\subsection{Statistical Analysis}

Data from the questionnaire was encoded, entered in Microsoft Excel 2007 spreadsheet and checked prior to analysis. There were cases where farmers gave multiple responses to same questions, therefore percentages may not add to 100. Data was analysed using SAS for Windows, version 9.1 (SAS Institute 2003). Frequencies and percentage variable occurrences were calculated using cross tabulation (PROC FREQ) and logistic regression was used to investigate how farmworkers perception of pesticide exposure, and health was influenced by their socio economic parameters. The logistic regression also investigated how the odds of using protection were affected by farmworkers belief variables.

\section{Results}

\subsection{Socioeconomic Background}

Table1. Socio-economic background of vegetable farmworkers interviewed

\begin{tabular}{cc}
\hline Farmers' background & Summary of responses (\%) \\
\hline Age category (years) & 0 \\
$\leq 20$ & 51.79 \\
$21-30$ & 33.93 \\
$31-40$ & 14.29 \\
$41-50$ & 83.93 \\
Males & 16.07 \\
Females & 91.07 \\
Male headed & 8.93 \\
Female headed & 23.21 \\
Educational background & 23.21 \\
Certificate & 8.93 \\
Diploma & 37.51 \\
Bachelors degree & 3.57 \\
Secondary school & 3.57 \\
Non formal & \\
Primary school & 32.14 \\
Work experience & 32.14 \\
Six months -year & 19.64 \\
One Year-two years & 14.29 \\
Two - five years & 1.79 \\
Less than six months & \\
More than five years &
\end{tabular}


The socio economic background of vegetable farmworkers provides the range of ages, gender and educational background of those interviewed (Table 1). Most farmworkers interviewed were males and majority was in a male headed household. Majority of respondents' age ranged between 21 to 30 years and fewer farmworkers were aged between 41 to 50 years (Table 1). Most respondents had attained secondary school education and the highest qualification was Bachelors degree (Table 1). The lowest education attained was non-formal education indicating that all farmworkers were literate. Most farmworkers had wok experience of between six months to two years and only $1.8 \%$ of the farmworkers had an experience of more than five years, indicating that the farmworkers had low experience in vegetable production. Only $14 \%$ of farmworkers interviewed had gone for training by extension services of the Botswana Ministry of Agriculture.

\subsection{Vegetable Crops Grown and Their Pests}

The most commonly grown vegetable was tomato (75\%) followed by Swiss chard (64\%), sweet pepper (60\%), cabbage and rape, each 58\%. The less popular vegetables grown were butternut squash (29\%), onions (14\%), watermelons $(7.14 \%)$ and the least grown crop was kale (2\%). All farmworkers interviewed considered pests as the major constraint to vegetable production. Most farmworkers (85\%) considered diamond back moth (Plutella xylostella $\mathrm{L}$ ) as the most important pest in vegetable production. P. xylostella was followed by cabbage aphid (Brevicoryne brassicae L) (66\%), spidermites (Tetranychus spp.) (45\%), cutworms, (Agrotis spp.) (41\%), whiteflies (Bemisia spp.) (39\%) and fruit flies (Dacus spp.) (34\%). The other pests mentioned in order of importance were stink bug (Nezarla viridula L) (21\%), cabbage webworm (Hellula undalis F.) (18\%), thrips (Thrips tabaci Lind.) (14\%), birds (14\%) and leaf miner (Liriomyza spp. ) (9\%).

\subsection{Vegetable Farmers' Use of Pest Management Tactics}

The results showed that control measures were used against pests in all the farms where interviews were done. Eighty six percent of farmworkers used pesticides to control pests. The use of pesticides was significantly associated with educational background $\left(\chi^{2}=7.38, \mathrm{P}=0.007\right)$ and experience $\left(\chi^{2}=4.92, \mathrm{P}=0.027\right)$ of farmworkers. In addition to pesticide use cultural control methods were also used namely weeding $(98 \%)$ crop rotation $(89 \%)$, pesticides $(86 \%)$, cultivation $(71 \%)$, and resistant varieties $(50 \%)$. The other cultural control methods used included intercropping (48\%), crop sanitation (27\%), manipulation of planting dates $(21 \%)$, soil amendment (13\% and biopesticides (2\%).

Table 2. Type of pesticides used by farmworkers§

\begin{tabular}{cccc}
\hline Active ingredients & WHO hazard class & No. of farmers & Pesticides class $^{\text {Pyrethroid }}$ \\
\hline Cypermethrin & II & 39 & Pyrote $^{(1)}$ \\
Dimethoate & II & 39 & Organophosphate $^{(1)}$ \\
Chlorpyripfos & II & 32 & Organophosphate $^{(1)}$ \\
Carbaryl & II & 28 & Carbamates $^{(1)}$ \\
Copper oxychloride & III & 27 & Inorganic-copper $^{(\mathrm{t})}$ \\
Mancozeb & U & 26 & Dithiocarbamate $^{(\mathrm{t})}$ \\
Deltamethrin & II & 24 & Pyrethroid $^{(1)}$ \\
Endosulfan & II & 22 & Organochlorine $^{(\mathrm{i})}$ \\
Alphamethrin & II & 20 & Pyrethroid $^{(1)}$ \\
Malathion & III & 17 & Organophosphate $^{(1)}$ \\
Methomyl & IB & Carbamates $^{(1)}$ \\
Chlorphenapyr & II & 13 & Pyrazole $^{(1)(a)}$ \\
Alpha-cypermethrin & II & 11 & Pyrethroid $^{(1)}$ \\
Abamectin & Not listed & 10 & Avermetin $^{(\mathrm{a})}$ \\
Carbofuran & IB & 10 & Carbamates $^{(1)(\mathrm{n})}$ \\
Diazinon & II & 10 & Organophosphate $^{(1)}$ \\
Dicofol & III & 8 & Organochlorine $^{(\mathrm{a})}$ \\
Demeton-s-methyl & IB & 7 & Organophosphate $^{(1)}$ \\
Fenamiphos & IB & 1 & Organophosphate $^{(1)(\mathrm{n})}$ \\
\hline
\end{tabular}

$\S$ Pesticides classes according to WHO's classification; $1 \mathrm{~A}=$ extremely hazardaous; $1 \mathrm{~B}=$ highly hazardous; $\mathrm{II}=$ moderately hazardous; III = slightly hazardous; $\mathrm{U}=$ Unlikely to present acute hazard in normal use; $\mathrm{i}=$ insecticides; $\mathrm{f}=$ fungicides; $\mathrm{a}=$ acaricides; $\mathrm{n}=$ nematicides.

The results in Table 2 show that 19 pesticides (active ingredients) were used by farmworkers to control pests in peri- urban areas of Gaborone. The type of pesticides included two fungicides, two nematicides, two acaricides and 17 insecticides. Amongst these, some pesticides belong to insecticides and acaricides as well as insecticides 
and nematicides (Table 2. Cypermethrin and demethoate were the most commonly used pesticides by farmworkers and chlorpyripfos was the second most commonly used pesticide. The rest of pesticides used in descending order of importance are shown in Table 2. Most vegetable farmerworkers (48\%) applied pesticides on weekly basis, followed by those who apply every two weeks (14\%), three times a week (8\%), once a month $(7 \%)$, every three weeks $(5 \%)$, twice a week $(4 \%)$, and $1 \%$ applied twice a month. Only $9 \%$ of farmworkers applied pesticides based on the amount of damage done by pests on their crops.

3.4 Pesticides Safety

Table 3. Results of logistic regression showing relationship between farmers' social background and their beliefs and practices towards risk associated with pesticides exposure

\begin{tabular}{|c|c|c|c|c|c|c|c|}
\hline $\begin{array}{c}\text { Dependent } \\
\text { variable }\end{array}$ & $\begin{array}{c}\text { Farmers' } \\
\text { social } \\
\text { background }\end{array}$ & Coefficient & SE & Wald $\chi^{2}$ & P-value & Odd ratio & $95 \mathrm{CI}$ \\
\hline \multirow[t]{7}{*}{ Become sick } & Intercept & -7.320 & 4.790 & 3.770 & 0.110 & & \\
\hline & Age & 0.813 & 0.595 & 1.867 & 0.172 & 2.255 & $0.72-7.24$ \\
\hline & gender & -0.161 & 1.3520 & 0.014 & 0.906 & 0.251 & $0.011-5.91$ \\
\hline & Household & -1.383 & 1.612 & 0.736 & 0.391 & 0.852 & $0.06-12.05$ \\
\hline & Education* & 1.075 & 0.484 & 4.924 & 0.027 & 2.929 & $1.134-7.56$ \\
\hline & Expereince & 0.246 & 0.421 & 0.343 & 0.558 & 1.279 & $0.561-2.92$ \\
\hline & Training* & 2.437 & 1.075 & 5.143 & 0.023 & 11.440 & $1.392-94.02$ \\
\hline \multirow[t]{7}{*}{ Children sick } & Intercept & 21.627 & 278.300 & 0.006 & 0.938 & & \\
\hline & Age & 1.161 & 0.768 & 2.285 & 0.131 & 3.193 & $0.709-14.39$ \\
\hline & gender & 11.232 & 278.200 & 0.002 & 0.968 & $>999.999$ & $<0.001->999.999$ \\
\hline & Household & -1.284 & 1.491 & 0.741 & 0.389 & 0.277 & $0.015-5.15$ \\
\hline & Education* & 0.700 & 0.670 & 1.090 & 0.297 & 2.013 & $0.54-7.48$ \\
\hline & Expereince & 0.066 & 0.523 & 0.016 & 0.900 & 1.068 & $0.383-2.98$ \\
\hline & Training* & 4.571 & 1.336 & 11.700 & 0.001 & 96.662 & $7.042->999.999$ \\
\hline \multirow{7}{*}{$\begin{array}{l}\text { Future health } \\
\text { problems }\end{array}$} & Intercept & -6.48 & 7.590 & 0.730 & 0.393 & & \\
\hline & Age & 0.070 & 0.910 & 0.010 & 0.941 & 1.070 & $0.18-6.38$ \\
\hline & gender & -10.82 & 203.800 & 0.002 & 0.958 & $<0.001$ & $<0.001->999.999$ \\
\hline & Household & 8.740 & 203.800 & 0.003 & 0.966 & $>999.999$ & $<0.001->999.999$ \\
\hline & Education* & 0.820 & 0.810 & 1.020 & 0.314 & 2.273 & $0.46-11.22$ \\
\hline & Expereince & 0.380 & 0.660 & 0.330 & 0.567 & 0.683 & $0.186-2.52$ \\
\hline & Training* & 4.700 & 1.630 & 8.270 & 0.004 & 110.042 & $4.47->999.99$ \\
\hline \multirow{7}{*}{$\begin{array}{l}\text { Exposure to } \\
\text { pesticides }\end{array}$} & Intercept & -6.770 & 3.490 & 3.760 & 0.053 & & \\
\hline & Age & 0.680 & 0.490 & 1.940 & 0.163 & 1.972 & $0.759-5.12$ \\
\hline & Gender & 0.130 & 1.380 & 0.010 & 0.926 & 1.136 & $0.076-16.92$ \\
\hline & Household & -1.250 & 1.130 & 1.210 & 0.271 & 0.288 & $0.031-2.65$ \\
\hline & Education* & 0.290 & 0.290 & 0.940 & 0.332 & 1.331 & $0.747-2.37$ \\
\hline & Expereince & 0.300 & 0.350 & 0.720 & 0.396 & 1.351 & $0.675-2.70$ \\
\hline & Training* & 2.600 & 0.990 & 6.900 & 0.009 & 13.471 & $1.937-93.78$ \\
\hline \multirow{7}{*}{$\begin{array}{l}\text { Protective } \\
\text { clothing }\end{array}$} & Intercept & 22.520 & 8.370 & 7.240 & 0.007 & & \\
\hline & Age & 0.820 & 0.870 & 0.880 & 0.347 & 2.264 & $0.412-12.44$ \\
\hline & gender & -16.380 & 213.600 & 0.010 & 0.937 & $<0.001$ & $<0.001->999.999$ \\
\hline & Household & 13.100 & 213.600 & 0.000 & 0.951 & $>999.999$ & $<0.001->999.999$ \\
\hline & Education* & -1.870 & 0.610 & 9.490 & 0.002 & 0.154 & $0.047-0.51$ \\
\hline & Expereince & -2.430 & 0.930 & 6.820 & 0.009 & 0.088 & $0.014-0.55$ \\
\hline & Training* & -1.460 & 1.750 & 0.690 & 0.405 & 0.232 & $0.007-7.2$ \\
\hline \multirow{7}{*}{$\begin{array}{l}\text { Protection } \\
\text { from } \\
\text { exposure }\end{array}$} & Intercept & 32.160 & 535.900 & 0.010 & 0.928 & & \\
\hline & Age & 1.280 & 0.780 & 2.700 & 0.100 & 3.580 & $0.782-16.39$ \\
\hline & gender & -13.48 & 294.300 & 0.002 & 0.964 & $<0.001$ & $<0.001->999.999$ \\
\hline & Household & 11.290 & 294.300 & 0.000 & 0.969 & $>999.999$ & $<0.001->999.999$ \\
\hline & Education* & -0.580 & 0.390 & 2.210 & 0.137 & 0.558 & $0.259-0.26$ \\
\hline & Expereince & -1.110 & 0.600 & 3.350 & 0.067 & 0.331 & $0.101-1.08$ \\
\hline & Training* & -13.010 & 176.900 & 0.010 & 0.941 & 0.001 & $<0.001->999.999$ \\
\hline
\end{tabular}

*significant $P \leq 0.05$ 
Eighty two percentage of the farmworkers interviewed considered pesticides as harmful to humans and the environment. The perception of pesticides harm was significantly associated with educational background $\left(\chi^{2}=\right.$ 6.59; $\mathrm{P}=0.020)$. All of the farmers interviewed $(100 \%)$ said that they read and followed the directions on the pesticide containers. Most farmworkers (85\%) believed that there were greater chances for them to experience health problems associated with pesticide exposure in the future. The knowledge of pesticide exposure increased significantly with training in pesticide application and safety (Table 3). Fifty percent of farmworkers believed they were exposed to pesticides while working in the fields. The knowledge of pesticide exposure was significantly associated with farmworkers training in pesticides application and safety (Table 3). Majority (82\%) believed that there were some ways of protecting themselves from exposure to pesticides but this was not significantly associated with their socioeconomic background (Table 3).

Only the perception of farmworkers who had gone for training on the use of pesticides was significantly associated with the belief that children born to them will be affected by pesticides (Table 3). Forty two percent of farmworkers believed that they may become sick by being exposed to pesticides in the vegetable farms. The fear of being sick from pesticide exposure was significantly associated with education background and training of farmworkers on pesticides use (Table 3). Most farmworkers (80\%) used protective clothing when applying pesticides. Educational background and experience of farmworkers was significantly associated with the use of protective clothing (Table 3). The perception of experiencing future health problems cuased by pesticide exposure was the most significant predictor of using protective clothing $\left(\mathrm{OR}=0.086,95 \% \mathrm{CI}, 0.016-0.45 ; \chi^{2}=\right.$ 8.33; $\mathrm{P}=0.004)$. The rubber boots were used by most farmers $(n=45)$ to protect their feet from pesticides followed by use of overall $(n=43)$ and rubber gloves $(n=43)$. Forty farmworkers used face masks, followed by the use of long sleeved shirt $(n=36)$, goggles/glasses $(n=32)$, long pants $(n=26)$, plastic clothes $(n=25)$ and cap, helmet or hat $(\mathrm{n}=24)$.

\section{Discussion}

The results from this study showed that tomatoes, Swiss chard, sweet pepper, cabbage and rape were the most commonly grown vegetables in the peri-urban areas of Gaborone in Botswana. In the previous country-wide study, tomato and sweet pepper were less common compared to rape, cabbage, and Swiss chard (Obopile et al., 2008). The results suggest that there was an increase in demand for tomatoes and sweet pepper since the last survey which was done six year ago. However a plausible explanation could be that more tomatoes were grown during warmer summer months when the current study was conducted because they are sensitive to frost when grown in winter. Conversely, fewer Brassica crops were grown because of higher pest incidences associated with higher temperatures of summer months.

Farmworkers considered arthropod pests as the most important constraint to vegetable production. Like in previous studies (Obopile et al., 2008; Munthali, 2009) the current study showed that diamond back moth, cabbage aphid, spidermites and cutworms were the most important pests of vegetables in Botswana. While cultural control methods of vegetable pests were mentioned, most farmers relied heavily on pesticide for management of pests. Over reliance on pesticides was reinforced by high number of farmers that sprayed their crops on weekly basis regardless of the presence of pests or damage symptoms. Most of the active ingredients used by vegetable farmers during this study are classified either as extremely hazardous or highly hazardous by World Health Organisation (WHO, 2005). This has implications on the safety and health of farmworkers due to high risks associated with pesticides use (Dinham, 2003).

Majority of farmers considered pesticides as harmful to humans and the environment. The knowledge of pesticide harm to humans increased with their educational background, indicating that more educated farmworkers were aware of hazards associated with pesticides exposure. These findings were confirmed by high numbers of mature and experienced farmworkers who mentioned that they read labels affixed to the pesticide containers before using them. There are inconsistent findings about farmworkers' reading of pesticide labels in literature. In Brazil Waichman et al. (2007) reported that most farmers did not read pesticide labels while in Turkey all farmers that were interviewed said that they read labels (Isin \& Yildirim, 2007), which is consistent with our results.

Most farmers especially with background training on the use of pesticides were concerned that their exposure to pesticides will affect their health and to lesser extent that of children born to them in the future. Interestingly most of them were aware of the ways to protect themselves from exposure to pesticides. The validity of this response was reinforced by a high number of respondents who used protective clothing in this study. Similar results were reported by McCauley et al. (2002) who found high responses to the question of whether adolescence farmworkers used protective clothing in Oregon, USA. 
Farmers' perceptions of risks related to pesticide exposure was more associated with their educational background, training and experience than their age, gender or household status. The trend was also observed in Lesotho where lack of education and training on pesticide safety was reportedly exposing famers to more risks of exposure and possible pesticide poisoning (Mokhele, 2011). Thus educational background, training on pesticide use from rural training centres might explain high percentage of farmworkers that read labels and being aware of pesticide harm during application. However percentage of farmworkers that received pesticide training was still low (14\%) suggesting that more training on efficient and safe use of pesticides is still needed to maintain higher level of pesticide awareness and minimize risks associated with pesticide exposure. Also people handling pesticides are now required by the law to attend an Agrochemical course at Botswana College of Agriculture before they are issued with license to sell, handle and apply pesticides. The study on risk and hazard associated with pesticides use on urban horticulture need to be extended to other urban areas of Botswana to establish a nationwide perspective.

\section{Acknowledgements}

This study was supported by funds from the Ministry of Education and the Botswana College of Agriculture.

\section{References}

Central Statistics Office (CSO). (2006). Population projections for Botswana: 2001-2031. Ministry of Agriculture, Gaborone, Botswana.

Dinham, B. (2003). Growing vegetables in developing countries for local urban populations and export markets: problems confronting small-scale producers. Pest management Science, 59, 575-582. http://dx.doi.org/10.1002/ps.654

FAO. (2006). The State of Food Insecurity in the World.

Isina, S., \& Yildirim, I. (2007). Fruit-growers' perceptions on the harmful effects of pesticides and their reflection on practices: The case of Kemalpasa, Turkey. Crop Protection, 26, 917-922. http://dx.doi.org/10.1016/j.cropro.2006.08.006

Madisa, M. E., Assefa, Y., \& Obopile, M. (2010). Assessment of Production Constraints, Crop and Pest Management Practices in Peri-Urban Vegetable Farms of Botswana. Egypt. Acad. J. biolog. Sci., 1, 1-11.

Miller, G. T. (2004). Sustaining the Earth, 6th edition. Thompson Learning, Inc. Pacific Grove, California.

McCauley, L. A., Sticker, D., Bryan, C., Lasarev, M. R., \& Scherer, J. A. (2002). Pesticide knowledge and risk perception among adolescent Latino farmworkers. Journal of Agricultural Safety and Health, 8, 397-409.

Mokhele, T. A. (2011). Potential health effects of pesticide use on farmworkers in Lesotho. S. Afr. j. sci, 107, 7-8. http://dx.doi.org/10.4102/sajs.v107i7/8.509

Munthali, D. C. (2009). Evaluation of cabbage varieties for resistance to the cabbage aphid. African Entomology, 17, 1-7. http://dx.doi.org/10.4001/003.017.0101

Obopile, M., Munthali, D. C., \& Matilo, B. (2008). Farmers' knowledge, perceptions and management of vegetable pests and diseases in Botswana. Crop Protection, 27, 1220-1224. http://dx.doi.org/10.1016/j.cropro.2008.03.003

Pedigo, L. P., \& Rice, M. E. (2006). Entomology and Pest Management. (5th ed.). Prentice Hall.

Quandt, S., Arcury, T., Austin, C., \& Saavedra, R. (1998). Farmworker and farmer perceptions of farmworker agricultural chemical exposure in North Carolina. Human Organization, 57, 359-368.

SAS Institute. (2003). SAS users guide: statistics. SAS Institute, Cary, NC.

Vaughan, E. (1993). Chronic exposure to an environmental hazard: Risk perceptions and Self-protective behavior. Health Psychology, 12, 74-85. http://dx.doi.org/10.1037/0278-6133.12.1.74

United Nations Population fund. (2007). State of world population, unleashing potential for urban growth, New York

Waichman, A. V., Eveb, E., \& da Silva, Nina, N. C. (2007). Do farmers understand the information displayed on pesticide product labels? A key question to reduce pesticides exposure and risk of poisoning in the Brazilian Amazon. Crop Protection, 26, 576-583. http://dx.doi.org/10.1016/j.cropro.2006.05.011

WHO. (2005). The WHO recommended classification of pesticides by hazard and guidelines to classification. 